\title{
Psychiatric Referrals from the Police
}

\section{Variations in disposal at different places of safety}

E. RASSABY, Research Officer and A. Rogers, Research Officer, National Association for Mental Health, 22 Harley Street, London W1

Section 136 of the Mental Health Act (MHA) 1983 authorises the police to take a mentally disordered person from 'a place to which the public have access' to a place of safety in order to be assessed by a doctor and an approved social worker. The person may be detained in the place of safety for up to 72 hours. Despite increasing controversy, the provision survived a heated parliamentary debate virtually unchanged from the 1959 Act. During the passage of the Mental Health Bill through Parliament, concern was expressed about the considerable variation in its use. ${ }^{1}$ Psychiatric examination of the provision has often been in comparison to compulsory admission provisions and the research populations have generally been confined to persons admitted to one hospital only. ${ }^{2.3 .4}$ Although some researchers have recognised the variations in the way the provision operates, ${ }^{5.6}$ there has been no systematic examination of these variations. An important question is whether these variations result in differences in patient care and this question is largely unexplored. In the first part of a three part study of $s 136^{*}$ the researchers set out to examine this question.

Our preliminary work suggested that the procedural variations apparent in the operation of sl36 were associated with the place of safety used for assessment. In the course of these preliminary enquiries we established that the two places most commonly used for assessment were a psychiatric hospital (or unit) and a police station, the former being the preferred place in London and the latter in other parts of the country. However, the wide definition in the Act as to what constitutes a place of safety (s135 MHA 1983 and 1959) permits many other places to be used and we discovered some innovations on the two basic models within the London area; these included the use of a casualty unit and a day hospital as places of safety. We set out to examine whether persons referred by the police to different places of safety received different 'disposals' (the word is used to refer to the outcome of the assessment in the same sense as the term 'court disposal').

\section{The Study}

Description of the places of safety. The three places of safety chosen include the two traditional settings, a psychiatric hospital and a police station, and one innovative

- The second part of the study concerns an analysis of cases referred by the police by means of interviews with the arresting officers. The third phase is a follow up of cases referred to a psychiatric unit and a psychiatric hospital in the Greater London area. Further details are available from the researchers. setting, an emergency and assessment unit (EAU). The three places serve discrete catchment areas in Greater London and are associated with a number of procedural differences in relation to police referrals.

The psychiatric hospital is situated on the outskirts of London and accepts referrals primarily from an inner London area as well as from a small local catchment area. People resident in those areas, or of no fixed abode (NFA) and arrested there by the police, are taken to the hospital where they are seen by a psychiatrist.

The police station is on the outskirts of north London and is used as the place of safety for people of NFA arrested in the local area and for those resident there. An arrested person is detained in the police station and assessed there by a doctor and social worker from a crisis intervention team (CIT) based in the psychiatric unit of the local hospital. The distinctive philosophy of the CIT (based on the management of psychiatric illness in the community and antipathetic to the medical model of psychiatric diagnosis and treatment) suggests that this setting cannot be regarded, in certain respects, as representative of other police stations which are used as places of safety.

The EAU is a 24-hour walk-in unit which is attached to, but operates relatively independently of, in-patient facilities of a psychiatric hospital. People of NFA found in the catchment area of the hospital or people resident there who are arrested by the police are taken to the unit where they are seen by a psychiatrist. The unit operates a system of 'guesting' (the person remains in hospital, usually overnight but sometimes for longer, but is not formally admitted) ${ }^{8}$ which provides a means of short term crisis management as well as an opportunity for further assessment.

The population consisted of all police referrals to the two settings between 1 January 1982 and 31 December 1983, irrespective of whether there was a formal acknowledgement of the use of $\mathrm{s} 136$ by the police or by the assessing professional(s). This wide definition was necessary because of the absence of any definitive indicator of the provision. This has resulted in ambiguity on the part of all those involved as to what does and does not constitute a s 136 case and what distinguishes such a case from an informal police referral. A small number of cases were excluded on the grounds that the referral was not initiated by the police, i.e. the decision regarding referral was made by another professional with the police providing assistance only. These included cases where the police were returning absconding patients to hospital, transferring patients from prison or special hospitals or assisting other professionals in bringing patients to a psychiatric facility. 
TABLE I

Immediate and final disposals of people referred to the three places of safety

\begin{tabular}{|c|c|c|c|}
\hline & $\begin{array}{c}E A U \\
(\mathrm{n}=158) \\
\%(\mathrm{~N})\end{array}$ & $\begin{array}{c}\begin{array}{c}\text { Hospital } \\
(\mathrm{n}=140)\end{array} \\
\%(\mathrm{~N})\end{array}$ & $\begin{array}{c}\text { Police station } \\
(\mathrm{n}=28) \\
\%(\mathrm{~N})\end{array}$ \\
\hline \multicolumn{4}{|l|}{ Immediate disposal } \\
\hline Discharged & 29.7(47) & $2.1(3)$ & $28.6(8)$ \\
\hline $\begin{array}{l}\text { Admitted informally } \\
\text { Admitted under Part II }\end{array}$ & $24.7(39)$ & $3.6(5)$ & 39.3(11) \\
\hline MHA & $7.6(12)$ & $2.1(3)$ & $10.7(3)$ \\
\hline Admitted under $\mathrm{s} 136$ & $0.7(1)$ & $91.4(128)$ & - \\
\hline Guested & 29.7(47) & - & - \\
\hline \multirow[t]{2}{*}{ Cases not known } & $7.6(12)$ & $0.7(1)$ & $21.4(6)$ \\
\hline & $\begin{array}{c}\chi \mathrm{sq}=424.4 \\
\mathrm{df}=4 \\
P<0.0001^{* *}\end{array}$ & & \\
\hline \multicolumn{4}{|l|}{ Final disposal } \\
\hline Discharged & $45.6(72)$ & $21.4(30)$ & As above \\
\hline Admitted & 43.9(69) & $75.7(106)$ & As above \\
\hline \multirow{2}{*}{ Cases not known } & $10.8(17)$ & $2.8(4)$ & As above \\
\hline & $\begin{array}{c}\chi s q=23.80 \\
\mathrm{df}=1 \\
P<0.0001^{* *}\end{array}$ & & \\
\hline
\end{tabular}

**The Police Station data were excluded from statistical tests. Missing data were excluded from calculation of $\chi$ sq.

A standardised coded schedule was devised and amended after a short piloting period. Information on each referral was obtained from records kept at the settings and from police documentation; information about police referrals at the police station setting was obtained from records kept by the crisis intervention team rather than by the police, whose own documentation does not record the decision taken on assessment. Information was collected under the following headings: sociodemographic characteristics, police procedure, assessment and disposal.

It was recognised that the 'immediate disposal' (i.e. the action taken following referral such as admission or guesting) might only be to provide a further period of assessment. Immediate disposal, therefore, was distinguished from 'final disposal', which was considered to be the action taken following the expiry of any periods which could be considered to be extended periods of assessment.

Table I presents the immediate and final disposals of people referred to the three places of safety. The data relating to the police station are not an accurate reflection of the disposals at that setting. This was because the system of record keeping by the crisis intervention team did not, in many instances, include the referral agent and thus it was not possible to distinguish police referrals from other referrals. The figures above include only those clearly marked as police referrals and are a considerable underestimate of the actual number of police referrals. Indeed, during the period of data collection the crisis intervention team monitored the number of police referrals over a one month period: the number during that month was 11 police referrals and if this was extrapolated to an annual figure the number would be similar to the other two settings. For this reason the data on police station referrals were excluded from statistical comparison. It is included in the table only as a broad indication of the range of disposals at that setting.

The table shows that the immediate and final disposals are significantly different in the hospital and EAU. In the EAU most referrals were either immediately discharged or guested and a substantial group were admitted informally to hospital. Of those guested, $53.1 \%$ were subsequently discharged, $34 \%$ were admitted informally and $4.3 \%$ were admitted under section. In the hospital the vast majority of referrals were admitted under section 136 and very few were discharged. Of those admitted under $\mathbf{1 3 6} 90 \%$ remained under the provision until 72 hours had expired. At the expiry of the provision, $50 \%$ were admitted informally to hospital, $21.1 \%$ were discharged and $28.8 \%$ were admitted under a section of the Mental Health Act.

The two places remain significantly different across final disposal. In the EAU almost half the referrals were discharged while a much smaller percentage were discharged from the hospital. Of those who were admitted on final disposal, the use of compulsory powers was significantly greater $(P<0.05)$ in the hospital, where $36.8 \%$ of admissions were under section, than after assessment at the EAU, where the comparable figure was $20.3 \%$. 


\section{Comment}

The difference in immediate disposals between the two settings are dramatic. In the hospital setting the very high number of admissions under s136 suggests that the decision regarding disposal is routine rather than one based on clinical, social or other individual considerations. In contrast, there is a variety of disposals following expiry of the provision, suggesting that individual assessment is occurring at the end of the 72 hours. In this sense, s136 is being used as a provision for short term compulsory admission rather than as a means of obtaining an immediate assessment of a person's psychiatric state.

This hospital is not unique in this practice. The researchers' preliminary enquiries at a large number of hospitals in the Greater London area suggest that the practice of admitting under $\mathbf{} 136$ for a 72 hour period is widespread in London. Indeed it is this practice which accounts for the apparently disproportionate numbers of s1 36 cases for London in the DHSS figures (In 1982, 86\% of all s136 admissions occurred in the areas of the four Thames Regional Health Authorities). ${ }^{8}$ The findings are worrying. It was clearly not the intention of the legislators that the provision should be used in this way, for there are other sections which permit detention for a short period (s2 MHA 1983/s25 MHA 1959). Moreover, the section clearly refers to assessment and not to admission. The practice of routine admissions for $\mathbf{7 2}$ hours also raises important civil liberties issues. There were some patients in our population who were considered not to be mentally ill at the initial assessment but were nevertheless detained under s136 for 72 hours. Others, though mentally ill, would clearly not fit the criteria for compulsory admission. If, as is likely, the provision has been misinterpreted, then some clear guidance from the Mental Health Act Commission is due. (Although this study examined persons referred by the police under previous legislation, the relevant provision is virtually unchanged under the 1983 Act and the researchers' current work suggests that the same practices are currently operative).

In contrast, persons taken to the EAU were assessed immediately and a wide range of disposals was available. Many persons discharged were given follow-up appointments at the unit-a facility which was not readily available at the hospital due to the distance from its catchment area population. Persons requiring admission were admitted informally or under Part II of the Act and in only one case was a person admitted under $\mathrm{s} 136$. The facility for guesting was widely used as a means of obtaining a further assessment and, in this sense, might fulfil a similar purpose to admission under $\mathrm{s} 136$. in the hospital setting. People were sometimes guested for two or three nights while arrangements for their care in the community were made.

The data on final disposal show that the differences were not confined to immediate short term disposal but were related to the person's longer term care as well. A number of factors might account for these findings. Differences between the referral populations is one possible factor. A comparison of the populations shows a higher number of persons of no fixed abode referred to the hospital setting and a higher proportion of persons of Afro-Carribean origin referred to the EAU. However, neither of these factors is associated with immediate or final disposal and the populations are comparable on other sociodemographic characteristics. Thus sociodemographic differences do not appear to account for the differences in disposal between the hospital and EAU; nor are there any significant diagnostic differences between the two populations which might explain the differences in final disposal.

We would suggest that the type of assessment facility is an important factor in explaining the different disposal patterns. The higher proportion of admissions in the hospital might be due, in part, to a predisposition to use available hospital beds in preference to out-patient forms of care. Similarly, the higher proportion discharged from the EAU might be due to the availability of follow-up facilities and self-referral in case of further crises. The conceptual independence of the EAU from in-patient services might also lessen the predisposition to admission in doubtful cases.

The greater use of compulsion at the hospital is notable and again the facilities and circumstances of the assessment might be an important element here. For example, there may be a 'knock-on effect' whereby persons assessed while being detained (i.e. under s136 in the hospital) are more likely to be subsequently detained, while persons assessed as out-patients or during guesting are less likely to be admitted under section. The influence of a person's legal status at assessment on the subsequent decisions regarding his/her care is an area requiring further investigation.

The widespread use of police stations as the place of safety outside London points to the need to assess and compare assessments and disposals there with assessments and disposals at hospital settings. The data in this study suggest that, despite the policy of the assessing CIT, there was a relatively high proportion of admissions to hospital, perhaps indicating the severity of the psychiatric condition of these police referrals. Whether or not assessments at police stations result in fewer hospital admissions than at hospital settings requires a more thorough investigation than was possible in this study. Another shortcoming of the present study was the lack of reliable information concerning discharged patients. For example, although many people referred to the EAU were offered some form of follow-up care, we were unable to assess to what extent that care was used and whether persons discharged subsequently relapsed. Thirty-four people were arrested by the police on multiple occasions during the study period (one person was brought to the EAU seven times during the two year period), thus casting some doubt on the efficacy of the disposal in those cases. Similarly, we could not assess the benefits to those people who were admitted to hospital after referral. Such an evaluation is underway in the third phase of the study by means of an in depth prospective study of cases referred to two hospitals.

The study has important implications for the planning of future services. The imminent closure of large psychiatric 
hospitals which currently serve as places of safety provides the opportunity to reassess the type of facilities which are appropriate for the assessment of psychiatric emergencies and, if necessary, to rationalise the different services that have developed over the years. This study suggests that the type of assessment facility might, to some extent, predetermine the form of care provided. One is led to question

\section{REFERENCES}

${ }^{1}$ Hansard (1982) 18 October, pp 99-100.

${ }^{2}$ SZMUKLER, G. I. (1981) Compulsory admissions in a London borough: II. Circumstances surrounding admission: service implications. Psychological Medicine, 11, 825-838.

${ }^{3}$ EILEnBerg, M. D. \& Whatmore, P. B. (1962) Police admissions to a mental observation ward. Medicine, Science and the Law, 2, 96-100.

${ }^{4}$ Rounn, H. R. (1965) Unprosecuted mentally abnormal offenders. British Medical Journal, 1, 831-835. whether hospital-based assessment, including assessment in psychiatric units, has any place in a community-oriented mental health service or whether a facility within the community (there are many facilities, apart from police stations, which could be considered) is more likely to result in a community-based form of care.

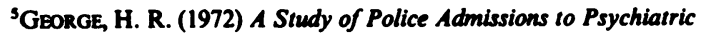
Hospitals. MD Thesis, University of London.

'Harrison, G., Inachen, B., Sutth, J. \& Morgan, H. G. (1984) Psychiatric hospital admissions in Bristol: Il. Social and clinical aspects of compulsory admission. British Journal of Psychiatry. $145,605-611$.

'Meng Hoor LM (1983) A psychiatric emergency clinic: a study of attendances over six months. British Journal of Psychiatry, 143, 460-466.

'Hansard (1984) 24 January, p. 550.

\section{Conference Report}

\section{International Conference on Gender Identity}

A two day conference on the theme of transsexualism was held at Charing Cross Hospital on 11-12 December 1986. The hospital is the site of the major British gender identity clinic; it was established by the late Dr John Randall and the surgical work was conducted by Mr Philip who pioneered the successful male to female operative technique of phallectomy and vaginoplasty which has now been widely adopted. The continuation of Mr Philip's work after his retirement by another surgeon has emphasised the conviction of the Charing Cross team that important work is being carried out and that full surgical reassignment must be available for carefully selected people who have shown that they can live in, and will only be content in, the opposite gender role.

The conference was national rather than international although the major Canadian centre at the Clarke Institute, Toronto, was represented. Addresses covered a broad range of themes from the literary style of transsexual autobiographies to the hepatotoxic effect of methyltestosterone, and from the work of the speech therapist in the team to the latest surgical development in phalloplasty which uses a radial artery flap to create the urethra. The present legal disabilities of transsexuals were discussed and an interesting paper on classification clarified the distinction between transsexualism and homosexuality yet noted the curious variants in the relationship of gender identity to sexual orientation. A survey of outcome was reported and Dr Mate-Kole, research psychologist at Charing Cross Hospital and the organiser of the conference, concluded the meeting with a list of topics for further research; these included better outcome evaluations, study of endocrine and neuropsychological aspects of gender dysphoria, and a wider understanding of the patients interrelationships with their families and their partners.

All the speakers and participants were enthusiastic about the study of gender dysphoria and the continued endeavour to improve the quality of life for transsexual people. Professor Hirsch said that the gender identity work at Charing Cross will continue but he pointed out that 150 new referrals and 700 follow-up patients a year imposed a considerable strain on the resources of the staff and the hospital; he concluded with an appeal to interested psychiatrists to establish regional teams in other parts of the country. In addition to taking the weight off the Charing Cross Hospital team, this would have the additional considerable advantages of convenience for the patients and closer knowledge of the aspects of the lives and relationships of transsexual people which are so necessary for good assessment and selection for the arduous procedure of gender reassignment.

Charles Mate-Kole and I should like to hear from any readers who would be interested to form a research and study group for the problems of gender identity.

PhILIP SNarth

Department of Psychiatry

St James's University Hospital

Leeds LS9 7TF 